\title{
PERCEPÇÃO DA PAISAGEM DO PARQUE EUCLIDES DOURADO NO MUNICÍPIO DE GARANHUNS - PE
}

\author{
Maria Betânia Moreira Amador ${ }^{1}$
}

RESUMO: O trabalho que se apresenta aborda importante parque urbano em Garanhuns - PE, que se denomina Euclides Dourado sob a ótica da análise da paisagem. O mesmo possui uma dinâmica de uso peculiar que agrega cultura, lazer, esporte entre as principais funções. Trata-se de um espaço que evidencia uma cobertura vegetal que remete à suas origens e apresenta alguns problemas de ordem ambiental. Objetiva-se abordar algumas dessas questões, através da percepção que se tem desse parque, utilizandose à análise sistêmica. Para isso, recorreu-se ao levantamento temático associado ao uso das técnicas de observação, entrevistas e fotografias embasando, assim, as considerações aqui traçadas. Ressalta-se, que esse trabalho encontra-se inserido na pesquisa, em desenvolvimento, sobre o verde urbano e rural de municípios do Agreste Meridional de Pernambuco conduzido no âmbito de Grupo de Estudos Sistêmicos do SemiÁrido do Nordeste - GESSANE da Universidade de Pernambuco/Campus Garanhuns e cujos resultados estão sendo associados às outras pesquisas realizadas, em paralelo no contexto da iniciação científica, trazendo à tona elementos que dão suporte a uma melhor compreensão do verde no agreste semiárido em pauta.

Palavras-chave: Garanhuns. Verde urbano. Parque Euclides Dourado.

${ }^{1} \mathrm{Dr}^{\mathrm{a}}$ em Geografia, UPE/Campus Garanhuns. betaniaamador@yahoo.com.br. 


\section{INTRODUÇÃO}

As questões urbanas estão frequentemente, entrelaçadas com 0 ambiente demandando reflexões as mais diversas. Entre elas encontram-se aquelas relacionadas aos espaços livres da cidade, os quais se enquadram em categorias diversas. Estes espaços fazem parte do conjunto de espaços livres públicos urbanos que, dependendo do objetivo, podem ser vistos e analisados sob variadas formas, desde o caráter sóciocultural até aqueles que consideram os elementos biológicos tanto de ordem geográfica como estruturais paisagísticos. Nesse contexto, toma-se Carneiro; Mesquita(2000, p.20) citado por Bovo; Amorim (2012) que disponibilizam a seguinte definição para parques urbanos:

[...] espaços livres públicos com função predominante de recreação, ocupando na malha urbana uma área em grau de equivalência superior a uma quadra típica urbana, em geral apresentando componentes da paisagem natural, vegetação, topografia, elemento aquático, como também edificações destinadas a atividades recreativas, culturais e/ou administrativas.

De tal forma, no município de Garanhuns - PE em meio a malha verde constituída de avenidas arborizadas, rotatórias ajardinadas, jardins e quintais exibindo plantas diversas, ressalta-se dois importantes parques Euclides Dourado e o Ruben van der Linden localizados bem na área core da cidade, dos quais enfoca-se nesse trabalho apenas o Euclides Dourado em função de sua monótona vegetação, essencialmente de eucaliptos bem como da maior escassez de suporte bibliográfico. Logo, tenciona-se produzir algum material que contribua na construção de conhecimento a respeito desse espaço através de considerações sobre seu passado, geograficidade, dinâmica e utilidade pensados frente a organização do espaço garanhuense. Para isso, a metodologia se rege pela percepção da paisagem nu contexto ecogeográfico utilizando-se para isso, os aportes técnicos rotineiros da pesquisa qualitativa. 


\subsection{CONCEITO E HISTÓRICO DOS PARQUES URBANOS}

Ao se falar de parques, praticamente remete-se a vida das cidades e aos seus espaços, sejam públicos ou privados. O conceito de parque é relevante e sua concepção é tão antiga quanto a de cidade, inicialmente tido como lugar de caçadas e outras atividades como as políticas e celebrativas, quase sempre se situavam nas imediações das construções da aristocracia em grande parte do mundo antigo. Assim,

Ao longo da história das cidades, os espaços livres, que congregavam as pessoas para diferentes atividades físicas, sociais e políticas, refletiam padrões culturais constituídos a partir de peculiaridades sociais e econômicas. Tudo isso deixou marcas no projeto paisagístico do parque urbano (SÁ CARNEIRO, 2010, 22).

Tomando-se como referência essa mesma autora, vê-se que é na Europa do século XVII onde acontece o delineamento precursor dos parques atuais, principalmente na França e na Inglaterra pela necessidade da realeza ter um local apropriado para a prática de esportes, diga-se caçadas tanto que originalmente a palavra parque significava campo de caça. Esses parques foram de caráter privado até o início do século XVIII quando então, gradativamente passaram a ser de domínio público.

No século XIX ocorreu a transformação dos parques privados em públicos mediante o "Movimento dos Parques Públicos" em função, basicamente, do aumento da população nas cidades e de sua expansão devido à Revolução Industrial trazendo junto problemas de saúde e saneamento, além de altos índices de mortalidade. Sendo assim, o Manifesto reivindicava mais espaços livres que funcionariam como pulmões verdes (WELCH, 1991 citado por SÁ CARNEIRO, 2010, p. 28), além de contribuir para uma melhor socialização das classes operárias e introduzir a percepção de bem estar e também contribuir para a municipalização dos parques.

No Brasil, os parques públicos surgem no Rio de Janeiro com a vinda da família real em 1808, pois neste período teve início aqui a 'organização urbana', que consistia na limpeza das ruas, na criação da polícia militar, na criação da imprensa régia e na fundação do Banco do Brasil (BOVO; AMORIM, 2012). Sabe-se, ainda, que por influência 
européia se procurou reproduzir o desenho e arquitetura dos espaços públicos europeus, principalmente franceses. Também se importou a idéia de se procurar plantar espécies exóticas, desde que exuberantes e diferentes da vegetação local, visto que a massa verde e seus efeitos positivos no ambiente urbano é que fazem a diferença do parque em relação a outras áreas verdes.

Em geral, os parques urbanos passaram por inúmeras transformações entre as décadas de 1970 e 1980 destacando-se as suas diferentes funções sociais, tornando-se instrumento de socialização comunitária, incorporando características sócio-ambientais, com a intervenção e iniciativa pública, a finalidade de lazer e recreação e também, a conservação e preservação da natureza. É com essa diretriz que se passa ao enfoque do Parque Euclides Dourado situado na área central do município de Garanhuns-PE.

\subsection{HISTÓRICO E LOCALIZAÇÃO DE GARANHUNS-PE}

Garanhuns (Figura 1) é um município da Região de Desenvolvimento do Agreste Meridional na Mesorregião do Agreste, Microrregião de Garanhuns e seu nome tem várias versões, a mais conhecida refere-se a palavra indígena que indica sítio dos guarás, ou seja, cães selvagens e também de anuns, que é uma espécie de pássaro preto, distante da capital do estado $228,8 \mathrm{Km}$.

O município apresenta latitude 853'25" sul, longitude 36ำ29'34" oeste, estando a uma altitude média de 900 metros. Seu ponto mais alto é o Monte Magano com $1.030 \mathrm{~m}$ de altitude, seu rio mais importante é o Rio Mundaú. A área do município é de, aproximadamente, 467,80 km2 e população de 130.303 habitantes, segundo estimativas do IBGE para o ano de 2011. 

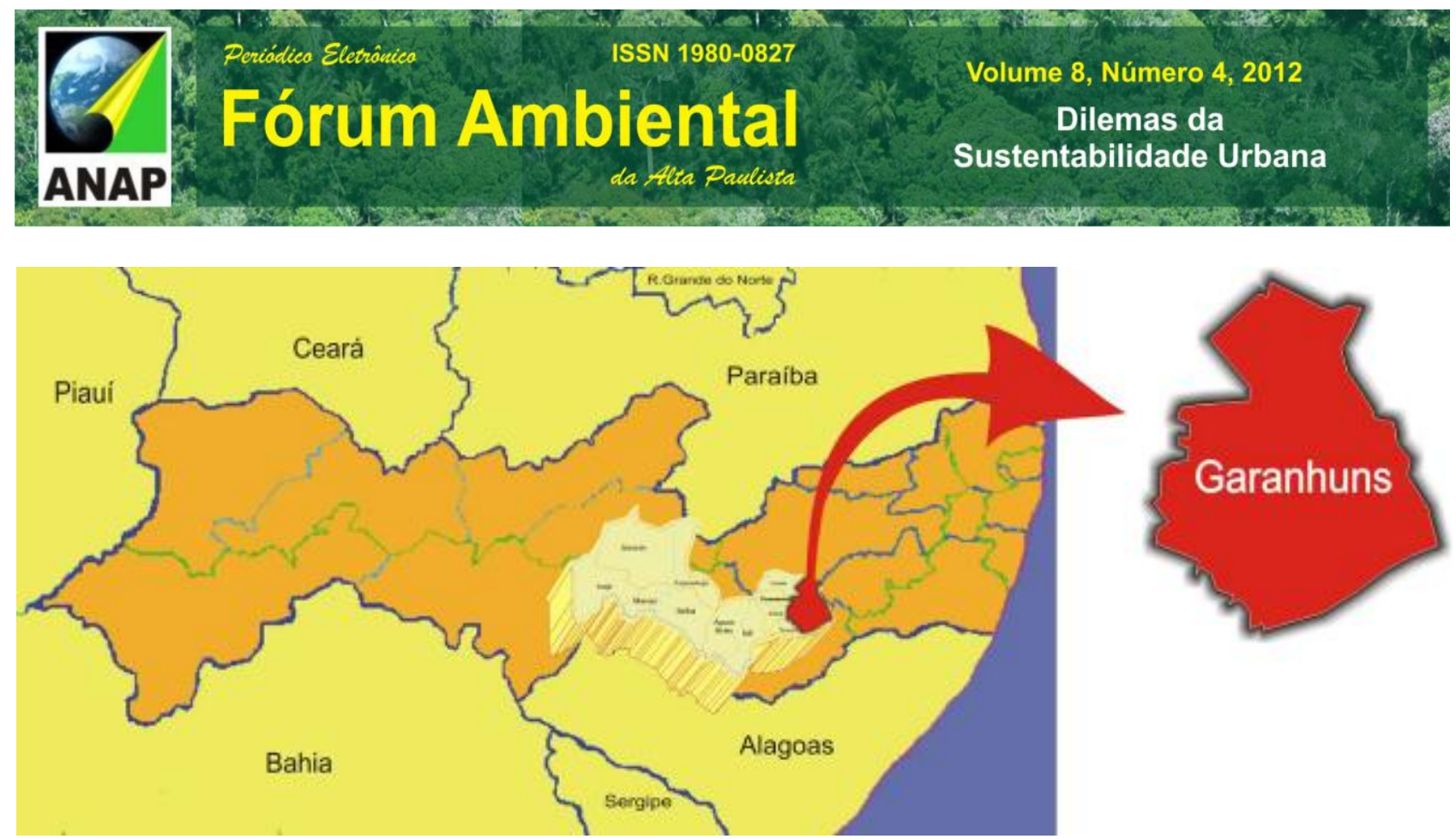

Figura 1. Localização do Município de Garanhuns

Fonte: www.ibge.gov.br - Mapas Interativos.In: GEOSISTEMAS, 200_.

Garanhuns apresenta clima do tipo mesotérmico com temperatura média anual de $30^{\circ} \mathrm{C}$, precipitação pluviométrica em torno de $871 \mathrm{~mm}$ com maior intensidade nos meses de março e julho. A vegetação predominante é a floresta subcaducifólica, sendo conhecida também pelas sete colinas que conformam a topografia da área urbana do município, o que determina declives e aclives acentuados, com poucas áreas planas na parte central da sede municipal.

A cidade, ao longo do tempo, sempre se destacou na agropecuária e no comércio que, no passado, foram beneficiados pela instalação da Estação Ferroviária em 1887 ligando Garanhuns ao Recife e, atualmente, as principais atividades econômicas desenvolvidas no município estão relacionadas ao setor terciário, de serviços e comércio.

\subsection{PARQUE EUCLIDES DOURADO}

Euclides da Costa Dourado (Figura 2) foi um importante político do município nas décadas de 1920 -1930. Segundo consta em Rêgo (1987), o mesmo foi Coletor Estadual nomeado pelo governador Dantas Barreto, em 1912 e, sub-prefeito em 1922. Porém, em 1924, assume a Prefeitura Municipal em virtude do falecimento do titular, prof. Luís Correia Brasil. Posteriormente, Euclides Dourado foi homenageado com seu nome dado ao antigo parque municipal da cidade. No entanto, ainda hoje, parte da população 




continua identificando esse espaço como Parque dos Eucaliptos (Figuras 3, 4 e 5), pois o mesmo é repleto de eucaliptos ocupando uma área com cerca de oito hectares. $\mathrm{O}$ eucalipto em si,é originário da Austrália e da Indonésia, considerada uma das principais fontes de matéria-prima para produzir papel. Pertence ao gênero Eucalyptus, que reúne mais de 600 diferentes espécies. Em território brasileiro, o eucalipto encontrou ótimas condições de clima e solo para se desenvolver, com crescimento mais rápido que nos demais países e alto índice de produtividade. Além da produção de celulose, também é fonte de carvão vegetal para gerar energia e de madeira sólida usada em móveis, pisos, revestimentos e outras aplicações na construção civil. Trata-se de uma árvore de uso múltiplo e, portanto, também é utilizada para males da saúde como cura de gripes, tosses entre outros.

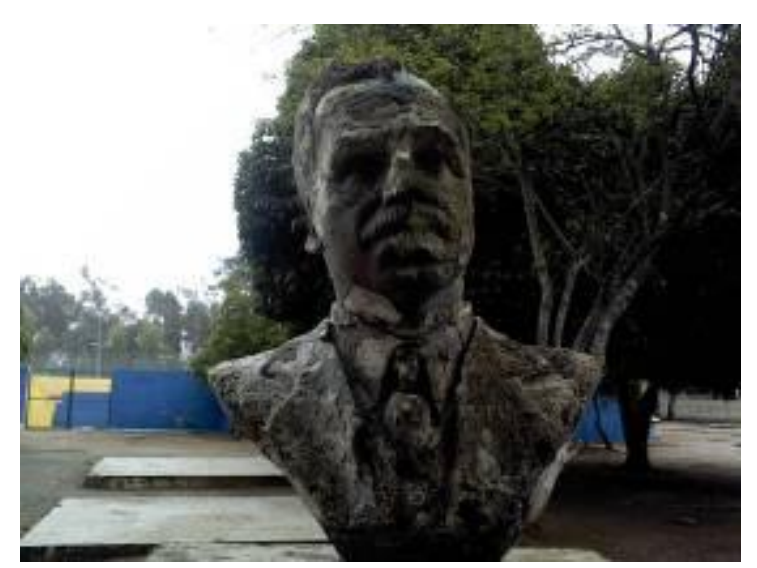

Figura 2: Busto de Euclides Dourado

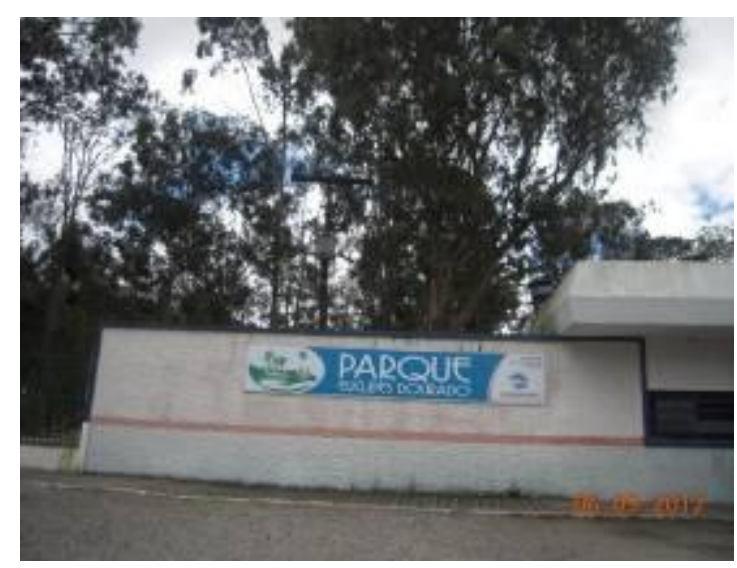

Figura 4: Entrada do Parque

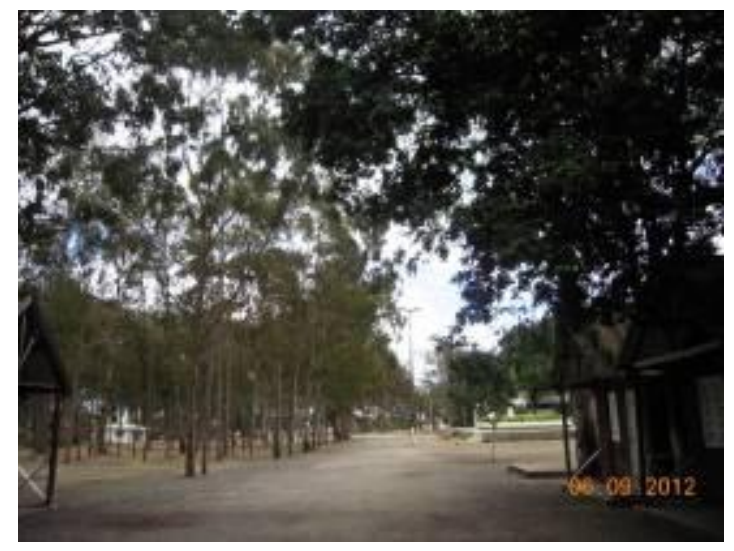

Figura 3: Parque dos Eucaliptos.

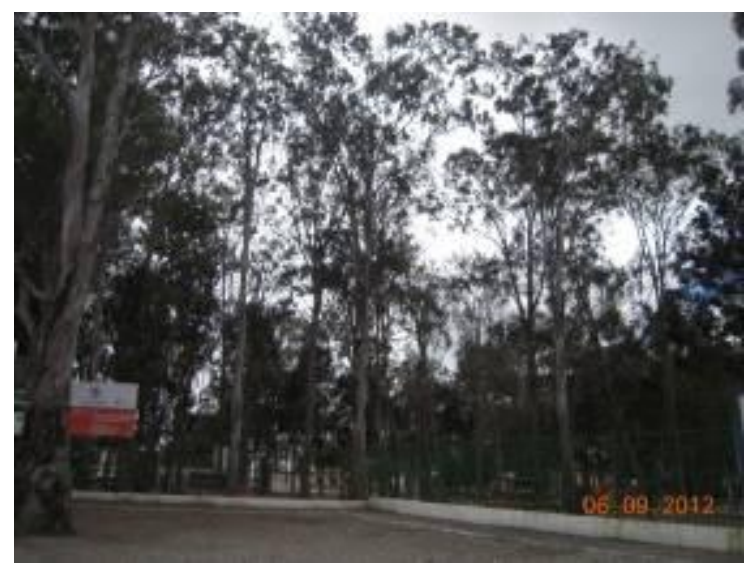

Figura 5: Visão frontal do Parque 


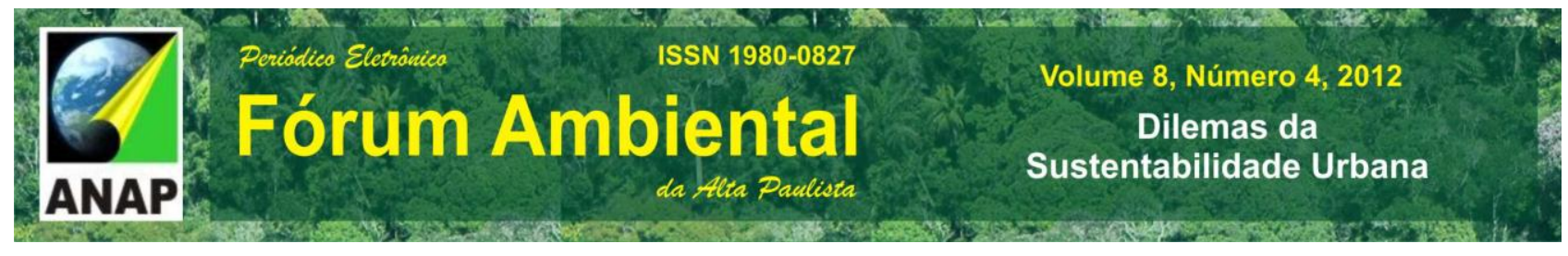

Os primeiros eucaliptos foram trazidos para o Brasil como planta ornamental em 1825 e plantados no Jardim Botânico do Rio de Janeiro.

Em 1868, a espécie começou a ser plantada para a produção de lenha e formação de barreiras contra o vento, inicialmente no Estado do Rio Grande do Sul. Sua expansão ganhou impulso nos primeiros anos do século XX com o trabalho do primeiro brasileiro a se interessar pelo estudo e cultivo da planta: o silvicultor Edmundo Navarro de Andrade. Na antiga Companhia Paulista de Estradas de Ferro, o cientista promoveu plantios de árvores para alimentar caldeiras das locomotivas e produzir dormentes, moirões e postes. Na época, foram introduzidas no Horto Florestal de Rio Claro (SP) as espécies de eucalipto cultivadas atualmente no País (BRACELPA, Disponível em: http://www.bracelpa.org.br/bra2/?q=node/136. Acesso em:10 out. 2012).

Em termos simbólicos e imagéticos, os eucaliptos do Parque Euclides Dourado(Figuras 6, 7 e 8), transmitem certa sensação de integração com o tempo e a história expressando, também, a geograficidade do lugar que segundo Dardel (2011), se refere ao modo da existência do homem e de seu destino, o qual pode ser relativamente apreendido pelas construções poéticas a seguir:

\section{O Parque dos Eucaliptos}

Que lindo plaino! Que docilidade Da natureza, quando rompe o dia, Ou quando a tarde cai, saudosa e fria. Naquela singular tranqüilidade!...

A viração, que silva e que se evade, O estandarte das flores, alicia, A adorável fragância que irradia A perfumosa vegetabilidade.

Os eucaliptos, de bailar não cessam, Enquanto os pombos, céleres, regressam À paz acolhedora do pombal.

Cair da tarde... E a viração fogueira Envolve, sussurrante e prazenteira. A vesperal paisagem do Arraial. (CYSNEIROS, 1979, p. 11)



Figura 6: Vista dos Eucaliptos no Parque Euclides Dourado Garanhuns-PE. Foto: M. Amador, 2012. 


\section{Periádica Eletránica

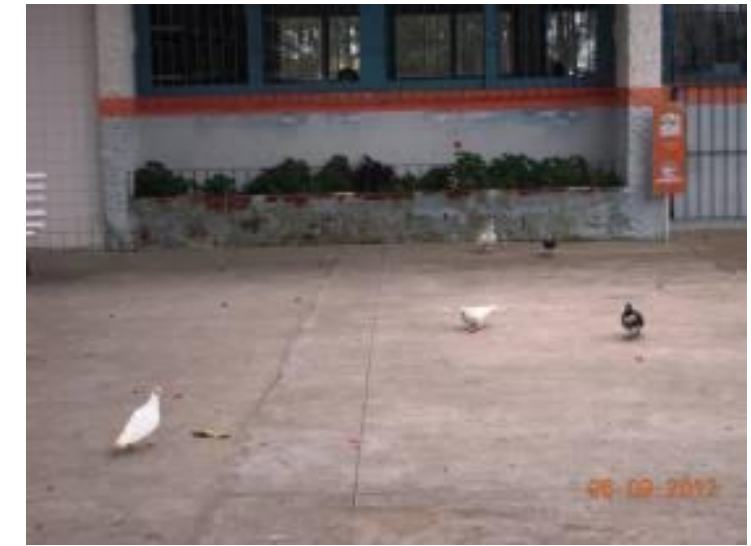

Figura 7: Pombos na parte externa da biblioteca Foto: M. Amador, 2012

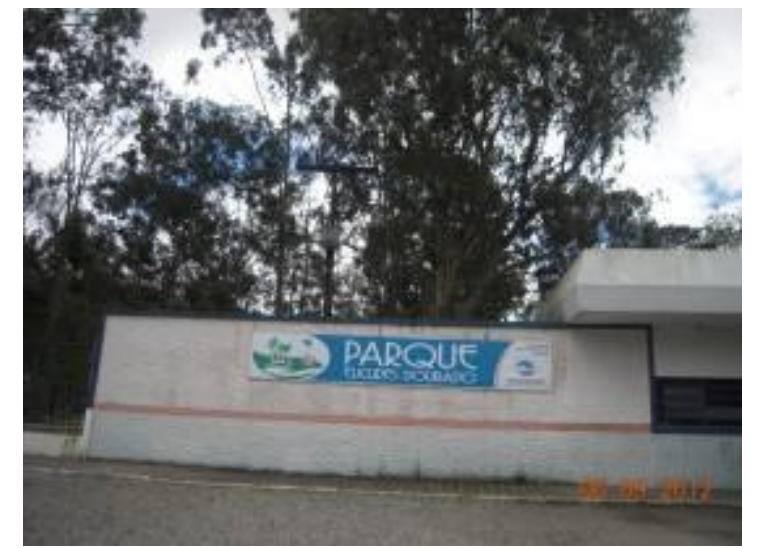

Figura 8: Vista frontal do parque Euclides Dourado Foto: M. Amador, 2012

Pode-se, então, apreender dessa poesia, que outrora o parque realmente exibia outra denominação já com a vegetação predominante de eucaliptos, mas da mesma forma que antes, a sensação de bem-estar é transmitida às pessoas que o freqüentam. Transparece, ainda, a coerência com o relevo local quando o autor inicia o texto e diz: "Que lindo plaino!", evocando claramente a idéia de relevo plano, informação importante tendo-se em vista ser o município incrustado entre as denominadas sete colinas e ademais, vai favorecer a função de lazer, que se sobressai frente às outras, que existe na atualidade. No sentido de dar mais solidez a reflexão cita-se mais uma poesia que enfoca a beleza, a vegetação e o imaginário popular do passado em relação ao parque dos eucaliptos permitindo assim, que se possa estabelecer alguns tênues vínculos com o presente. 

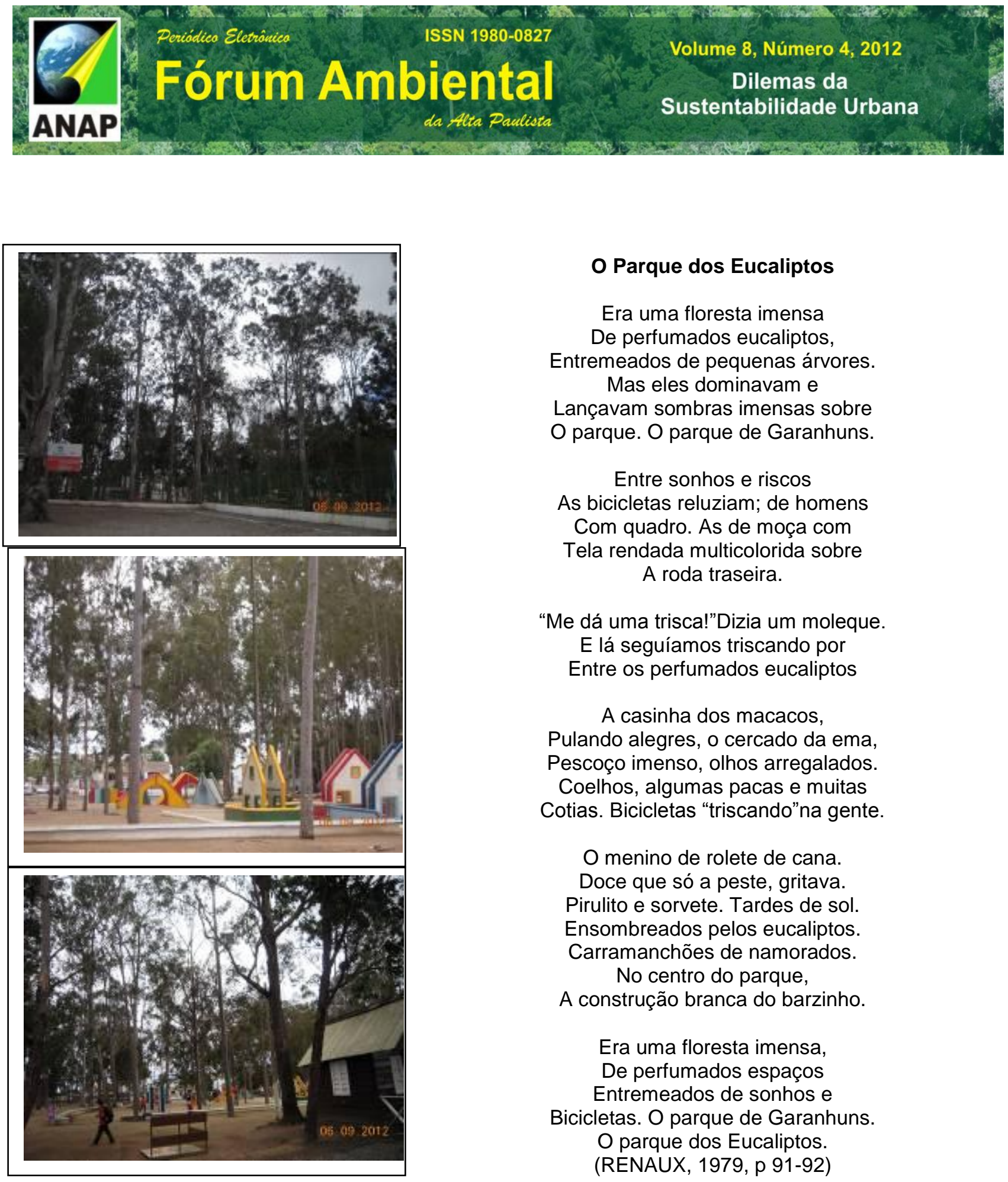

\section{O Parque dos Eucaliptos}

Era uma floresta imensa

De perfumados eucaliptos,

Entremeados de pequenas árvores.

Mas eles dominavam e

Lançavam sombras imensas sobre

O parque. O parque de Garanhuns.

Entre sonhos e riscos

As bicicletas reluziam; de homens

Com quadro. As de moça com

Tela rendada multicolorida sobre

A roda traseira.

“Me dá uma trisca!"Dizia um moleque.

E lá seguíamos triscando por

Entre os perfumados eucaliptos

A casinha dos macacos,

Pulando alegres, o cercado da ema,

Pescoço imenso, olhos arregalados.

Coelhos, algumas pacas e muitas

Cotias. Bicicletas "triscando"na gente.

O menino de rolete de cana.

Doce que só a peste, gritava.

Pirulito e sorvete. Tardes de sol.

Ensombreados pelos eucaliptos.

Carramanchões de namorados.

No centro do parque,

A construção branca do barzinho.

Era uma floresta imensa,

De perfumados espaços

Entremeados de sonhos e

Bicicletas. O parque de Garanhuns.

O parque dos Eucaliptos.

(RENAUX, 1979, p 91-92)

Através da leitura dessa poesia percebe-se que esse espaço, Parque Euclides Dourado, ao longo do tempo foi palco de lugar aprazível, de passeio e ao que tudo indica, em dado momento, exibiu uma fauna indicativa de zoológico, o que se confirma através da seguinte citação: "Foi transformado o Horto de eucaliptos em formoso Parque Zoológico com a denominação de Parque Municipal, hoje Euclides Dourado" (LEITE, 1983, p. 305). 




Dessa forma, quando o autor remete ao fato dos macacos, da ema e outros pequenos animais, isso faz com que se estabeleça uma conexão com um espaço/lugar/paisagem nos quais o ambiente, aparentemente, se mostrava mais equilibrado e em harmonia com diversas dimensões da sustentabilidade, quais sejam: social, econômica e ecológica evidenciando-se nas palavras dos autores poetas citados e que refletem o cotidiano aprazível da época. "O cotidiano tem, assim, sua leitura baseada na intuição obtida, associada à experiência dos habitantes locais" (CAMARGO, 2008, p. 101).

Com a diversidade no tempo, observa-se atualmente que o parque encontra-se, próximo ao centro da cidade (Figura 9) e passou a ser o lócus de práticas esportivas apresentando equipamentos como pista de caminhada (Figura 10), quadra de jogos como futsal e basquete (Figura 11), e também congrega área específica de recreação de crianças entre outros e, por ser de caráter municipal, ainda abriga uma biblioteca com sua área externa ajardinada, bem como nele se instalam, periodicamente, circos, parques de diversão entre outros.



Figura 9: Visualização da localização do Parque Euclides Dourado na malha urbana de Garanhuns-PE 


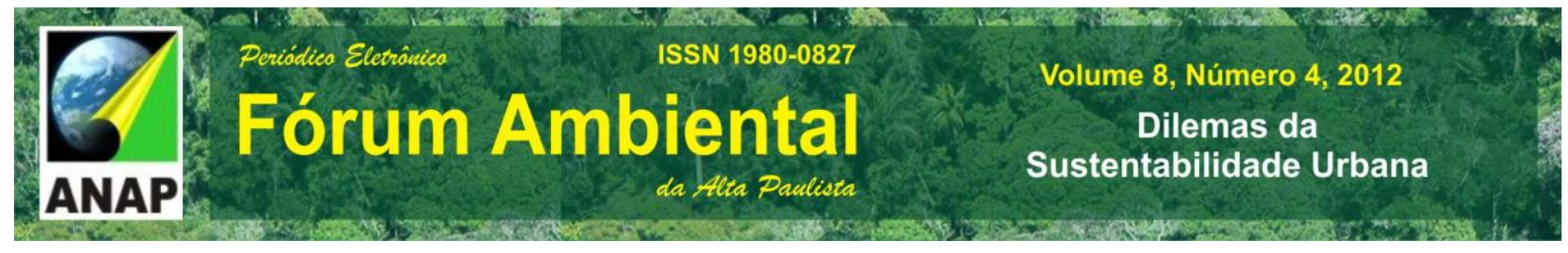

Como se pode ver na figura 9, nos termos apresentados, o Parque Euclides Dourado dispõe, ainda, de significativa área arborizada, mas uma paisagem monótona, limitante às condições plenas para o desenvolvimento de uma diversidade faunística e florística, naturalmente pensada.

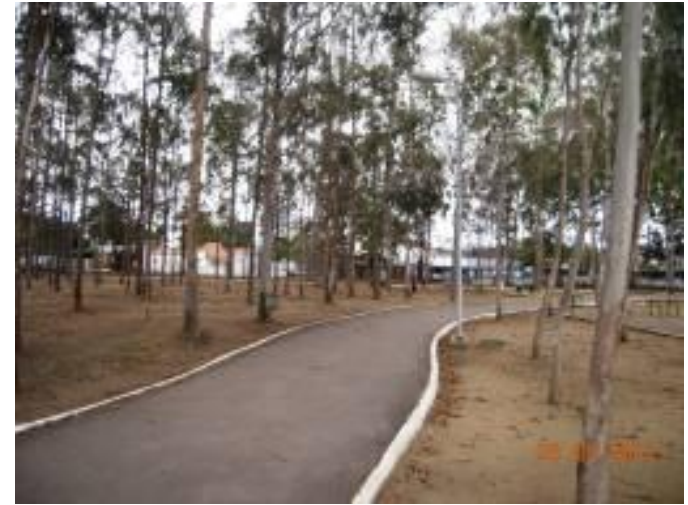

Figura 8: Pista de caminhada. Amador, 2012

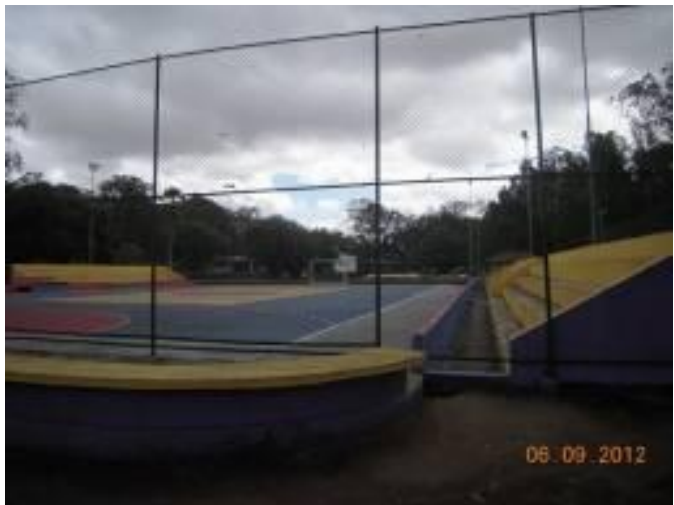

Figura 9: Quadra esportiva. Amador, 2012

Porém, o sentimento de pertencimento e a idéia introjetada pela população da possibilidade de bem-estar advinda da prática de exercícios físicos têm ressaltado nesse espaço, mais que qualquer outra do local, a dimensão social e a psicológica. A primeira pela "possibilidade de lazer que essas áreas oferecem à população" e, a segunda pela "possibilidade de realização de exercícios, de lazer e de recreação que funcionam como atividades "antiestresse" e relaxamento, uma vez que as pessoas entram em contato com os elementos naturais dessas áreas" (BARGOS; MATIAS, 2011, p. 181).

Porém, deve-se chamar a atenção mais uma vez, para o padrão simplificado da paisagem verde, a qual é constituída praticamente de uma única espécie: o eucalipto. Segundo informações obtidas, em décadas passadas esse espaço foi local de reflorestamento, principalmente dessa espécie exótica com a função definida para obtenção de madeira que abasteceria as locomotivas da ferrovia Great Western estabelecida em Garanhuns desde o século XIX, cuja rotina atendia desde passageiros à escoamento da produção, predominantemente agropecuária (Lima, 2009). Recorre-se, também, ao geógrafo Aziz Ab' Saber (1990) que diz serem os brejos nordestinos locais para reflorestamentos devido ao seu clima e hidrologia diversos, o que contribui para 
ocorrência de subespaços úmidos para abrigar florestas no interior dos sertões secos, através de certo número de modelos geo-hidroecológicos conhecidos como brejos de serra, cimeiras ou cumiadas, entre eles cita-se Baturité, Triunfo, Garanhuns e Serra Negra.

Logo, por conseguinte, acredita-se ter havido um plantio da espécie exótica Eucaliptos com o objetivo de fornecer lenha para as locomotivas da linha de trem projetada para Garanhuns-PE, ficando a plena confirmação dessa hipótese para um trabalho posterior em virtude da escassez de tempo e necessária pesquisa em fontes como a Companhia Inglesa Great Western associado ao levantamento da história via memória com os citadinos.

\subsection{CONCLUSÃO}

Entende-se que o parque abordado nesse trabalho é um equipamento importante e possui uma longa trajetória junto ao município considerado, adaptando-se às novas demandas da população ressaltando-se entre elas o uso como área de lazer, mas também é visível que a relação que está estabelecida no seio da população em geral, é de relativo afastamento do verde, mesmo que monótono, representado pelos eucaliptos presentes neste bem chamado parque urbano, difuso e de fundamental importância para o bem estar das pessoas e do ambiente em termos macro, entendo-se como local e municipal. O mesmo parece passar despercebido para a população que o freqüenta evidenciando interesse maior na oportunidade de se exercitar e encontrar amigos enfim, na socialização pura e simplesmente. Apesar de belo, razoavelmente bem cuidado, percebe-se não haver muita preocupação com os impactos ocasionados por ocasião de sua utilização em momentos festivos, nos quais turismo, música e comércio se fazem presentes com muita força que em si são atividades impactantes. O solo, por sua vez, apresenta-se sempre limpo, até mesmo das folhas e galhos que caem, compreende-se por um lado a necessidade de não dar oportunidade para animais peçonhentos mas que, por outro lado, pode prejudicar a micro e mesofauna que teoricamente existe em qualquer solo. Em alguns dias do ano ocorre, por exemplo, a presença de cigarras, emprestando um novo som e um novo manto ao solo pela queda de suas cascas ou exaesqueletos 
fazendo, de certa forma, companhia aos pombos tradicionalmente presentes, mas entregues à própria sorte. Nesse sentido, acredita-se e concorda-se com Vasco; Zakrzevski, 2010, serem os estudos da percepção ambiental essenciais para compreender as inter-relações entre o homem e o ambiente, suas expectativas, anseios, satisfações e insatisfações, julgamentos e condutas em relação ao espaço onde está inserido, julgando-se ser de fundamental importância ampla divulgação de tais trabalhos.

\section{REFERÊNCIAS}

Aziz Ab' Sáber. FLORAM: Nordeste Seco. Estudos Avançados. v.4 n.9. São

Paulo. Mai/Ago. 1990. ISSN 0103-4014. http://www.scielo.br/scielo.php?pid=S0103-

40141990000200007\&script=sci_ar. Acesso 29 set 2012.

AMADOR, Maria Betânia Moreira Amador. Sistemismo e sustentabilidade: questão interdisciplinar. São Paulo: Scortecci, 2011. ISBN

.Parques urbanos em Garanhuns - PE. III Seminário Nacional e I Seminário Internacional "O papel do Geógrafo no Contexto Social Atual”. 26 - 29 Set. 2012. Natal, UFRN, 2012. ISSN 2178-8804.

ASSIS PAULA, Flávia Maria; CAVALCANTi, Lana de Souza (Orgs.). A cidade e seus lugares. Goiânia: E.V., 2007.

BENINI, Sandra Medina; MARTIN, Encarnita Salas. Decifrando as áreas verdes públicas. Revista Formação, n.17, v.2, 2010.

BOVO, Marcos Clair; AMORIM, Margarete Cristiane de Costa Trindade. Efeitos positivos gerados pelos parques urbanos: um estudo de caso entre o Parque do Ingá e o Parque Florestal das Palmeiras no Município de Maringá/PR. Disponível em:

http://www.geo.ufv.br/simposio/trabalhos/trabalhos_completos/eixo8/041.pdf. Acesso em: 14 ago 2012.

BRACELPA. Eucalipto. Disponível em: http://www.bracelpa.org.br/bra2/?q=node/136. Acesso em: 10 out. 2012

DARDEL, Eric. O homem e a terra: natureza da realidade geográfica. Tradução de Werther Holzer. São Paulo: Perspectiva: 2011. ISBN 978-85-273-984-0.

FARAH, Ivete. Poética das árvores urbanas. Rio de Janeiro: Mauad x: FAPERJ, 2008.

FERRY, Luc. A nova ordem ecológica: a árvore, o animal e o homem. Tradução de Rejane Janowitzer. Rio de Janeiro: DIFEL, 2009. ISBN 978-85-7478-275-1. 
GEOSISTEMAS Engenharia e Planejamento Ltda. Plano de gerenciamento integrado de resíduos sólidos do município de Garanhuns. SECTMA - GOVERNO DE PERNAMBUCO, 200

LEITE, Afredo. História de Garanhuns. Recife, FIAM/Centro de Estudos de História Municipal, 1983.

LIMA, José Cláudio Gonçalves. Os sitiados: a hecatombe de Garanhuns: romance histórico. Recife: Ed. do Autor, 2009.

Localização do Município de Garanhuns. Disponível em: < www.ibge.gov.br>. Mapas Interativos. Acesso em: 12 out. 2012.

MOLICA, Silmar Gonzaga. [Re]florestamento. II Curso de Especialização em Silvicultura em nível de pós-graduação. Departamento de Ciência Florestal, Universidade Federal Rural de Pernambuco, 1995.

SÁ CARNEIRO, Ana Rita. Parque e paisagem: um olhar sobre o Recife. Recife: Ed. Universitária da UFPE, 2010.

RÊGO, Alberto da Silva. Os aldeões de Garanhuns, sua gente, seus jovens, suas associações, o mundo literário, os "players", os poetas, e árvores genealógicas. Recife, FIAM/Centro de Estudos de História Municipal, 1987.

REINAUX, Marcílio Lins. Garanhuns: a enevoada pérola fugidia. Crônicas, desenhos, poesias. Edição comemorativa. Recife: Gráfica e Editora Raiz. 1999.

VALENÇA, Pedro Jorge. Garanhuns, terra das águas - A cidade sofre racionamento e um colapso quase total. Correio Sete Colina on-line. Disponível em:

$<$ http://www.bluenet.com.br/correiosetecolinas/2002/11/30/opiniao2.html>. Acesso em 04 set. 2012. 